Homepage: http://epubs.icar.org.in/ejournal/index.php/JWR

\title{
DWAP 1531: An early maturing bold seeded bread wheat germplasm for warmer areas
}

\author{
SK Singh*, RP Gangwar and Pradeep Sharma \\ ICAR-Indian Institute of Wheat and Barley Research, Karnal-132001
}

Article History: Received: 15 July 2018, Revised: 10 August 2018, Accepted: 14 August 2018

Citation: Singh SK, RP Gangwar and P Sharma 20018. DWAP1531: An early maturing bold seeded bread wheat germplasm for warmer areas. Wheat and Barley Research, 10(2):120-122. doi.org/ 10.25174/2249-4065/2018/82263

*Corresponding author: sksinkgh.dwr@gmail.com

(C) Society for Advancement of Wheat and Barley Research

The wheat growing areas in the country has been divided into five mega zones and the wheat crop in four zones namely, North Western Plains Zone (NWPZ), North Eastern Plains Zone (NEPZ), Central Zone (CZ) and Peninsular Zone (PZ) experiences warmer climatic conditions during grain growth period. The wheat production is adversely affected in these areas as grain yield and its components were reported as a function of variable responses of different genotypes to heat in different stages of wheat development (Lillemo et al., 2005; Yildirim and Bahar, 2010). Grain mass is the most important character to confer heat tolerance (Reynolds et $a l ., 1994)$ but the variation among genotypes for grain yield under heat stress is due to a larger variation in number of spikelets per spike and number of grains (Shpiler and Blum, 1986). Lower grain yields were reported due to susceptibility of the genotype to heat during the grain filling stage as demonstrated by the reduction percentage in 1000-grains weight (Pimental et al., 2015). The effect of warmer climatic conditions on grain yield due to reduction in grain number and 1000-grains weight was also reported by Modarressi et al. (2010). Therefore, these traits along with spike length, were appointed by Farooq et al. (2011) as essential for selection of heat tolerant genotypes. Keeping these in view, it was felt that there is need to develop early maturing genotypes that can avoid warmer temperatures and, proper grain filling in these genotypes resulting in bolder seeds to sustain the adverse climatic conditions. Research efforts were made to combine adaptability traits into high yielding wheat varieties in order to get improved germplasm adapted to warmer areas. A large number of germplasm lines have been developed in the warmer area programme of the IIWBR, Karnal and being contributed in national nurseries for multi-location evaluation and sharing with cooperating centres. During 2015-16, a total of 12 wheat genotypes, developed in warmer area programme, were contributed in Yield Component Screening Nursery (YCSN). Among these, the germplasm line DWAP 1531 has been found promising for early heading and maturity possessing bolder seeds.

The germplasm line DWAP 1531 was developed from the cross PBW 343/VS1065. The female parental line PBW 343 was a mega variety for irrigated timely sown conditions of the north western plains zone as well as north eastern plains zone. The male parental line VS 1065 was selected from special CIMMYT nursery INDV96 received in 1996 with pedigree $\mathrm{K} 134$ (60)/VEE//BOW /PVN and parental history CM103578-6M-030Y-020Y010M-3Y-010Y-0M-0SY. The breeding methodology was modified pedigree bulk method wherein the spike selections were made in segregating generations and spikes selected from a progeny were bulked. After $\mathrm{F}_{6}$, ear to row was planted to get uniformity and more seeds and the promising rows were selected and harvested separately. After $\mathrm{F}_{7}$, the preliminary trials for yield and component traits were made and the promising entries were selected. The line DWAP 1531 was evaluated for yield and component traits and found early flowering and maturing with better yield component traits.

In order to evaluate at multi-locations through coordinated evaluation system, DWAP 1531 was contributed in the Yield Component Screening Nursery (YCSN) during 2015-16. The nursery consisted of 105 entries and four specific trait based checks. These were Lok 1 for 1000-grains weight, WH 147 for grain number/spike, 
HD 2009 for tillers/meter and DBW 17 as high yielding variety. During 2015-16, the pooled data from 25 locations across the country indicated that DWAP 1531 was found superior for grain number (55) and 1000-grains weight (47) as compared to the respective check varieties WH 147 and Lok 1 as indicated in Table 1 . Based on its superiority, DWAP 1531 was promoted for $2^{\text {nd }}$ year of evaluation in YCSN at 27 locations under AICRP on Wheat \& Barley.
During $2^{\text {nd }}$ year of evaluation, the pooled mean indicated its superiority for 1000-grains weight $(50 \mathrm{~g})$ as compared to check Lok $1(45 \mathrm{~g})$. The data of two years was pooled and mean values were worked out to know the stable superiority of the entry over the checks (table.1) where DWAP 1531 showed superiority over all the checks for grain number per spike (55) and 1000-grains weight of $49 \mathrm{~g}$.

Table 1: Performance of DWAP 1531 in Yield Component Screening Nursery during 2015-16 to 2016-17

\begin{tabular}{lccccccc}
\hline \multicolumn{1}{c}{ Traits } & Year & Locations & DWAP 1531 & Lok 1 & WH 147 & HD 2009 & DBW 17 \\
\hline $\begin{array}{l}\text { Grains } \\
\text { spike }\end{array}$ & 2015-16 & 25 & $55(31-80)$ & $48(29-67)$ & $53(37-73)$ & $52(41-65)$ & $50(34-63)$ \\
& $2016-17$ & 27 & $54(31-79)$ & $50(30-76)$ & $52(35-79)$ & $56(39-93)$ & $55(-)$ \\
\multirow{2}{*}{$\begin{array}{c}\text { 1000-grains } \\
\text { weight }\end{array}$} & $2015-16$ & 25 & $47(32-60)$ & $44(31-55)$ & $38(26-53)$ & $39(27-50)$ & $38(31-47)$ \\
& $2016-17$ & 27 & $50(33-57)$ & $45(32-56)$ & $39(27-51)$ & $38(28-47)$ & $42(39-46)$ \\
\multicolumn{2}{c}{ Mean } & $49(32-60)$ & $45(31-56)$ & $39(26-53)$ & $39(27-50)$ & $40(31-47)$ \\
\hline
\end{tabular}

After two years of evaluation in YCSN, the entry DWAP 1531 was contributed to the National Genetic Stock Nursey (NGSN) for multi-locational evaluation and sharing with the cooperating centres as potential donor for grain number and 1000-grains weight as identified from YCSN. The NGSN facilitates evaluation for more yield components namely days to heading and maturity, plant height, spike length in addition to grain number per spike and 1000-grains weight. It also includes evaluation of the entries for resistance to rust diseases and leaf blight in field conditions. During 2017-18, entry DWAP 1531 was evaluated in NGSN conducted at 34 locations alongwith check varieties Sonalika and HD 2967. Sonalika is the well known check for earliest flowering and maturity whereas HD 2967 is a high yielding mega variety for northern plains. The varieties namely DBW 17, HD 2009, WH 147 and Lok 1 which were used as checks during evaluation in YCSN were also included in the NGSN to make comparison of the test entry. Based on the pooled results of all the 34 locations (Table 2), it was found that DWAP 1531 had earliest flowering (74 days) and maturity (122 days) as compared to the check varieties. It also had good plant height $(95 \mathrm{~cm})$ that may be beneficial to get more straw in addition to very bold seeds (48g TGW) and longer spikes $(11 \mathrm{~cm})$ as compared to all the check varieties. In this way, trait-wise analysis indicated better performance of DWAP1531 for more than three traits in combination namely, early heading and maturity, 1000-grains weight and spike length compared to the respective best check variety.

Table 2: Mean performance of DWAP1531 from 34 locations in NGSN during 2017-18

\begin{tabular}{|c|c|c|c|c|c|c|c|c|c|c|c|}
\hline \multirow{3}{*}{$\mathrm{SN}$} & \multirow{3}{*}{ Genotypes } & \multicolumn{6}{|c|}{ Agronomic traits } & \multicolumn{4}{|c|}{ Disease resistance } \\
\hline & & \multirow{2}{*}{$\begin{array}{l}\text { Days to } \\
\text { heading }\end{array}$} & \multirow{2}{*}{$\begin{array}{l}\text { Days to } \\
\text { maturity }\end{array}$} & \multirow{2}{*}{$\begin{array}{l}\mathrm{Pl} \mathrm{ht} \\
(\mathrm{cm})\end{array}$} & \multirow{2}{*}{$\begin{array}{l}\text { Grains/ } \\
\text { spike }\end{array}$} & \multirow{2}{*}{$\begin{array}{l}\text { 1000-gr } \\
\text { wt (g) }\end{array}$} & \multirow{2}{*}{$\begin{array}{c}\text { Spike } \\
\text { length }(\mathrm{cm})\end{array}$} & \multicolumn{2}{|c|}{ Black rust } & \multicolumn{2}{|c|}{ Leaf blight } \\
\hline & & & & & & & & $\mathrm{HS}$ & $\mathrm{ACI}$ & HS & Av \\
\hline 1 & DWAP 1531 & 74 & 122 & 95 & 53 & 48 & 11 & $\mathrm{TS}$ & 0.6 & 35 & 22 \\
\hline $\mathrm{C} 1$ & DBW17(C) & 83 & 127 & 80 & 54 & 37 & 10 & $40 \mathrm{MR}$ & 3.3 & 46 & 11 \\
\hline $\mathrm{C} 2$ & HD2009(C) & 79 & 125 & 89 & 56 & 34 & 10 & $40 \mathrm{X}$ & 4.9 & 68 & 22 \\
\hline C3 & LOK 1(C) & 76 & 123 & 95 & 50 & 43 & 11 & $5 \mathrm{~S}$ & 2.6 & 46 & 23 \\
\hline $\mathrm{C} 4$ & WH147(C) & 84 & 126 & 90 & 55 & 39 & 10 & $10 \mathrm{MS}$ & 3.2 & 56 & 22 \\
\hline C5 & Sonalika $(\mathrm{C})$ & 81 & 127 & 86 & 52 & 38 & 9 & $80 \mathrm{~S}$ & 28.2 & 68 & 34 \\
\hline C6 & HD $2967(\mathrm{C})$ & 85 & 129 & 92 & 56 & 37 & 10 & $40 \mathrm{~S}$ & 10 & 57 & 22 \\
\hline
\end{tabular}


In NWPZ \& NEPZ, terminal heat stress is major abiotic factor that affect the wheat yield. On the other hand, early and late heats coupled with water scarcity are major abiotic factors in $\mathrm{CZ}$ and $\mathrm{PZ}$. The zone wise analysis was done by pooling centres in NWPZ and NEPZ together and CZ and PZ together for these yield component traits. Results indicated superiority of the DWAP 1531 for the traits studied in both the groups, i.e., NWPZ-NEPZ as well as CZ-PZ as shown in table 3 . The grain filling duration of DWAP 1531 was also highest that provides longer duration of grain development as represented by boldest seeds.

Table 3. Comparative performance of DWAP 1531 and checks for yield component traits in northern vs central-peninsular zones

\begin{tabular}{|c|c|c|c|c|c|c|c|c|c|c|c|c|}
\hline \multirow{2}{*}{ Genotypes } & \multicolumn{2}{|c|}{$\begin{array}{c}\text { Heading } \\
\text { (days) }\end{array}$} & \multicolumn{2}{|c|}{$\begin{array}{c}\text { Maturity } \\
\text { (days) }\end{array}$} & \multicolumn{2}{|c|}{$\begin{array}{c}\text { Plant } \\
\text { height }(\mathrm{cm})\end{array}$} & \multicolumn{2}{|c|}{$\begin{array}{c}\text { Grains per } \\
\text { spike }\end{array}$} & \multicolumn{2}{|c|}{$\begin{array}{c}\text { 1000-grains } \\
\text { weight }(\mathrm{g})\end{array}$} & \multicolumn{2}{|c|}{$\begin{array}{l}\text { Spike length } \\
(\mathrm{cm})\end{array}$} \\
\hline & $\begin{array}{l}\text { NW- } \\
\text { NE }\end{array}$ & $\begin{array}{l}\mathrm{CZ}- \\
\mathrm{PZ}\end{array}$ & $\begin{array}{l}\text { NW- } \\
\text { NE }\end{array}$ & $\begin{array}{l}\text { CZ- } \\
\text { PZ }\end{array}$ & $\begin{array}{l}\text { NW- } \\
\text { NE }\end{array}$ & $\begin{array}{l}\mathrm{CZ}- \\
\mathrm{PZ}\end{array}$ & $\begin{array}{l}\text { NW- } \\
\text { NE }\end{array}$ & $\begin{array}{l}\text { CZ- } \\
\text { PZ }\end{array}$ & $\begin{array}{l}\text { NW- } \\
\text { NE }\end{array}$ & $\begin{array}{l}\mathrm{CZ}- \\
\mathrm{PZ}\end{array}$ & $\begin{array}{l}\text { NW- } \\
\text { NE }\end{array}$ & $\begin{array}{l}\mathrm{CZ}- \\
\mathrm{PZ}\end{array}$ \\
\hline DWAP1531 & 78 & 59 & 124 & 106 & 102 & 88 & 57 & 51 & 45 & 48 & 12 & 10 \\
\hline DBW17 (C) & 87 & 69 & 127 & 114 & 84 & 77 & 56 & 53 & 36 & 36 & 10 & 10 \\
\hline HD2009 (C) & 83 & 65 & 127 & 111 & 93 & 83 & 57 & 55 & 33 & 33 & 10 & 10 \\
\hline LOK 1 (C) & 78 & 62 & 125 & 107 & 97 & 92 & 48 & 50 & 43 & 42 & 11 & 11 \\
\hline WH147 (C) & 88 & 70 & 127 & 113 & 94 & 86 & 57 & 54 & 37 & 38 & 10 & 9 \\
\hline Sonalika $(\mathrm{C})$ & 83 & 68 & 127 & 113 & 90 & 82 & 53 & 54 & 38 & 38 & 10 & 9 \\
\hline HD2967(C) & 90 & 70 & 130 & 115 & 95 & 91 & 57 & 56 & 38 & 37 & 10 & 10 \\
\hline
\end{tabular}

NW-NE- Mean for centres in NWPZ and NEPZ; CZ-PZ: Mean values for centres in CZ and PZ

These genotypes were also evaluated for resistance to rusts and leaf blight under natural conditions. The genotype DWAP 1531 was outcome of the wheat improvement programme for the warmer areas with special emphasis on central and peninsular India. In these zones, stem (black) rust and leaf blight diseases occur frequently and sometimes cause more damage to wheat crop. The black rust was appeared in NGSN entries at Indore, Vijapur, Junagadh of central zone and Pune and Wellington of the Peninsular zone. The leaf blight appeared at Sabour, Faizabad, Varanasi, Kalyani, Coochbehar, Burdwan of north eastern plains zone (NEPZ), Vijapur in CZ and Pune and Dharwad of PZ. Most of these locations are hot spot location for these diseases where these occur in natural condition. The average coefficient of infection (ACI) was calculated for rusts and average values were worked out for leaf blight based on 0-9 double digit score. The genotypes having ACI upto 10.0 for rust are considered as resistant and for leaf blight the limit of highest score and average values are 57 and 35, respectively for resistant genotypes (Anonymous, 2017). The results indicated that DWAP 1531 showed highly resistant reactions to stem rust (TS, ACI-0.6) and leaf blight (HS-35, Av-22) compared to the check varieties.

Based on above results, it may be concluded that the germplasm line DWAP 1531 was found promising donors for various traits especially earliness and bold seeds. This reflects its suitability to adaption in the areas experiencing warmer climate. Thus, the genotype DWAP 1531 can be further utilized as potential donor for these yield component traits in wheat improvement programmes.

\section{References:}

1. Anonymous. 2017. Progress report of AICROP on Wheat \& Barley, 2016-17. Crop Protection, ICAR-IIWBR, Karnal, Pp. 200.

2. Farooq J, I Khaliq, MA Ali, M Kashif, A Rehman, M Naveed, Q Ali, W Nazeer and A Farooq. 2011. Inheritance pattern of yield attributes in spring wheat at grain filling stage under different temperature regimes. Australian Journal of Crop Science, 5: 1745-1753.

3. Lillemo M, MV Ginkel, RM Trethowan, E Hernandez and J Crossa. 2005. Differential adaptation of CIMMYT bread wheat to global high temperature environments. Crop Science, 45: 2443-2453.

4. Modorresi M, V Mohammadi, A Zali and M Mardi. 2010. Response of wheat yield and yield related traits to high temperature. Cereal Research Communication, 38 (1): 23-31.

5. Pimentel AJB,JRASC Rocha, MA de Souza, G Ribeiro, CR Silva, ICM Oliveira. 2015. Characterization of heat tolerance in wheat cultivars and effects on production components. Revista Ceres, 62(2): 191-198.

6. Reynolds MP, M Balota, MIB Delgado, I Amani and RA Fischer. 1994. Physiological and morphological traits associated with spring wheat yield under hot, irrigated conditions. Australian Journal of Plant Physiology, 21: 717-730.

7. Shpiler L and A Blum. 1986. Differential reaction of wheat cultivars to hot environments. Euphytica, 35: 483-492.

8. Yildirim M and B Bahar. 2010. Responses of some wheat genotypes and their F2 progenies to salinity and heat stress. Scientific Research and Essays, 5: 1734-1741. 